\title{
Thomas J. Errico, Baron S. Lonner, Andrew W. Moulton (eds): Surgical management of spinal deformities
}

\author{
Saunders Elsevier, Philadelphia, 2009536 pp, num figs, Hardcover $€$ 205.00, \\ ISBN 978-1416033721
}

Pierre Kehr

Received: 16 August 2009 / Accepted: 18 August 2009 / Published online: 30 August 2009

(C) Springer-Verlag 2009

Another book on spinal deformities, once more! It's what I thought while flipping it. In fact going deeper into details, I found this book very useful with interesting analyses of the different subjects with the same plan: generalities, clinical presentation, imaging and treatment. At the end of each chapter we find "pearls and pitfalls" where the author gives his own practical experience. Finally, there is an illustrative case presentation on the pathology treated in the chapter. The book is divided into five chapters: General introduction/Principles, Pediatric Deformity, Adult Deformity, Perioperative consideration and the Future of Spinal Deformity Surgery. You can find with the book videotapes on the majority of the chapters treated in the book. In spite of its qualities the book is an American vision of the subject with the eye of Saint Louis Missouri with few place for European works except perhaps for sagittal balance: incidence and sagittal tilt are shyly evoked. In a word a good book that it's better to have but we can dream of something better. It's to the reader to choose.

No funds were received in support of this study.

Jean-Paul Steib

Strasbourg

P. Kehr $(\square)$

Strasbourg, France

e-mail: kehrpier@aol.com 